\title{
Os festivais GLBT de cinema $e$ as mudanças estético-políticas na constituição da subjetividade*
}

\begin{abstract}
Karla Bessa $^{* *}$
Resumo

Neste artigo traço um breve panorama do crescimento $e$ diversificação dos festivais GLBT de cinema e da visibilidade gay. A análise está centrada nas transformações que configuraram uma nova cinematografia denominada, no início dos anos 1990, de queer movie (Rich, 1991). Desde a pioneira edição de um festival de cinema gay e lésbico, em São Francisco no final dos anos 1970, houve uma significativa mudança nos filmes feitos pelo, ou voltados para o, público gay. Isso se faz notar da produção à exibição, incluindo aspectos narrativos e técnicas cinematográficas, o que provoca um repensar tanto da formatação-programação dos festivais, quanto do próprio cinema GLBT. Novas sensibilidades e subjetividades contrastam-se com as pioneiras cenas fílmicas de cunho militante-identitário, colocando questões sobre corpo, sexualidade e gênero.
\end{abstract}

Palavras-chave: Cinema Queer, Sexualidade, Festivais GLBT de Cinema.

\footnotetext{
* Recebido para publicação em outubro de 2006, aceito em março de 2007. Parte da pesquisa aqui apresentada foi desenvolvida no período de janeiro a dezembro de 2004, na University of Michigan, em estágio pós-doutoral financiado pela CAPES. Agradeço às numerosas contribuições, facilidades e, sobretudo, ao afeto proporcionado por Sueann Caulfield, bem como às preciosas dicas de Lawrence La Fontaine Stolkes e David Halperin. No decorrer da pesquisa contei também com a interlocução erudita e sempre bem humorada dos cinéfilos (entre outras coisas) Rodrigo Merheb e José Costa. Agradeço, ainda, a leitura instigante e minuciosa de Richard Miskolci e dos pareceristas. Uma primeira versão reduzida deste texto consta nos anais eletrônicos da Reunião da ANPOCS em 2005, Caxambu-MG. Agradeço a Plínio Dentzien a versão das citações.

*** Professora do Instituto de História, Universidade Federal de Uberlândia-MG. kambessa@uol.com.br
} 
Os festivais GLBT de cinema

GLBT Movie Festivals

and the Aesthetic-Political Changes in the Constitution of Subjectivity

\begin{abstract}
This article is an overview of the growth of GLBT film festivals and also of gay visibility. The focus will be on the analysis of the changes that configured a new cinematography called, at the beginning of the nineties, queer movies (Rich, 1991). Since the San Francisco Gay and Lesbian film festival at the end of the seventies, there was a significant change in the films made for or directed toward gay audiences. This could be noticed from production to exhibition, including narrative aspects and cinematographic techniques, leading one to rethink both the formattingprogramming of the festivals and the GLBT cinema itself. New sensibilities and subjectivities contrast with the pioneering film scenes from the militant-identitary matrix, raising questions on body, sexuality and gender.
\end{abstract}

Key Words: Queer Movies, Sexuality, GLBT Film Festivals. 
Nos anos 1990, em meio à proliferação dos diversos tipos e especialidades de festivais de cinema, incluindo os que contemplam as mudanças na tecnologia $e$ formatação dos filmes (curtas, VHS, Digital), destaca-se o boom de festivais gays $e$ lésbicos. A demarcação do que hoje se entende por um festival GLBT $^{1}$ foi, e ainda é, objeto de controvérsias. Embora pareça possuir um recorte claro - "gays, lésbicas, transgêneros e bissexuais" -, ficam as perguntas: existiria uma estética gay que serviu de critério para a seleção da filmografia exibida nos festivais? Ou ainda, bastaria que os filmes abordassem a temática, personagens e/ou situações homoeróticas? Algumas produções não abordam diretamente o cenário gay, mas incluem

1 A ênfase no "hoje" é relativa às mudanças no uso de siglas e às questões políticas e mercadológicas a elas associadas. Um exemplo é o Primeiro Festival de São Francisco (1976/1977) - nomeado San Francisco International Lesbian and gay film festival - e, recentemente, sua página na Internet traz a sigla LGBT uma tentativa de atualizar a nomeação da diversidade com a qual a comunidade homossexual se autonomeia. É interessante notar que alguns festivais privilegiam o termo lésbica no início da sigla e outros o gay. Gay/lésbica são termos que remetem ao contexto das lutas identitárias afirmativas durante a década de 1970. Gay (ou guei) também foi e é utilizado para pessoas que se identificam com o "estilo de vida gay", em contraposição à vida straight (heterossexual). GLBT é uma sigla internacional vinculada aos movimentos homossexuais a partir dos anos 1990, mas nem sempre é adotada com todas as "letras"; no Brasil, a letra T remete a "transgêneros" - que engloba travestis e transexuais. Nos anos 90 surgiu, no Brasil, a sigla GLS - Gays, lésbicas e simpatizantes -, ironizada por J.S. Trevisan como "um verdadeiro ovo de colombo conceitual". Essa sigla gerou polêmica por ser ambígua e possibilitar, ao mesmo tempo, maior "integração" e divulgação de atividades culturais claramente ligadas à homossexualidade, porém, apresentava o risco de esvaziar o potencial de luta, ao cativar o $\mathrm{S}$ (simpatizante - o gay friendly - traduzido de "modo simples e adequado ao nosso jeitinho") e tornar outra vez invisível o GL. O Festival Mix da Diversidade Sexual (1993), e o Mercado Mundo Mix foram pioneiros na utilização do GLS (Trevisan, 2000). Atualmente, as chamadas para o Festival, sítios de Internet e documentos utilizam mais a sigla GLBT. Na década de 1990 (inicialmente no EUA e posteriormente nos demais Festivais e outros produtos culturais), o uso do Queer surgiu como uma proposta de ruptura com o discurso identitário que marcava o movimento gay. No decorrer do texto, retomarei algumas das definições teóricas e políticas do termo queer. 
Os festivais GLBT de cinema

sexualidades consideradas fora dos padrões de normalidade heterossexual, como as práticas sado-masoquistas, e foram produzidas e/ou dirigidas por pessoas que se auto-identificam como gays.

De fato, a controvérsia existiu ao longo da década de 1990 e cada festival formulou suas "regras" e critérios de inscrição, instituindo uma convenção. Alguns festivais eram mais abertos a temáticas que "interessariam" ao público majoritariamente homossexual, outros, mais restritos, limitavam a oportunidade de produção e exibição (concorrendo a verbas para novos filmes) àqueles diretamente ligados ao tema $e$ à identidade, enfatizando o compromisso político com uma estética diferente dos filmes comerciais e possibilitando uma abordagem direta da homossexualidade sem passar pelos subterfúgios clássicos da indústria cinematográfica.

Em geral, os festivais dessa natureza priorizam películas sensiveis a questões como AIDS, discriminação, solidão e desafios e dificuldades de se "assumir" uma identidade gay, bem como reserva parte do repertório de exibição para filmes com forte conteúdo erótico. ${ }^{2}$

Um dos pontos de partida do circuito de festivais GLBT, nos anos 1990, é o fato de serem primeiramente constituídos e constituintes de práticas representacionais que visam tornar presente, de modo positivo, imagens (função de mimeses, muitas vezes espelhada; noutras, autocrítica e bem humorada) relativas ao universo "homo" e seus arredores.

A configuração dos festivais GLBT de cinema, naquilo que eles geram em termos de produção e consumo de bens culturais (materiais e imateriais), interage com a constituição da cena gay, ou seja, há uma relação entre os festivais GLBT, o circuito cinematográfico por ele concebido e o modo como essa dinâmica

2 Durante a pesquisa, consultei mais de 100 programações, disponibilizadas nos diferentes sites de Festivais nos EUA, Canadá, Europa, Ásia, Austrália e Brasil. Embora não tenha quantificado os dados, é perceptível a preponderância dos filmes que abordam o erotismo gay masculino em detrimento do feminino. 
compõe a produção de subjetividade e suas respectivas marcas de gênero nas urbis ${ }^{3}$ contemporânea, como aponta B. Ruby Rich:

Comecei a pensar nos festivais de cinema como o último refúgio da democracia neste nosso mundo cada vez mais controlado e manietado, o último lugar onde um verdadeiro discurso participatório pode ainda valer e onde pessoas de firmes convicções e mentes abertas podem a vir trocar opiniões, abrir mão do controle e ser mudadas para sempre pelo que acontece na tela (Rich, 2004).

Apesar do aspecto positivo destacado acima, permanece a questão se esses festivais estariam na mão do narcisismo típico da cultura contemporânea ou poderiam ser entendidos como espaços transgressivos de uma corporalidade e uma subjetividade convencionais já cultuadas pelo cinema. Estes festivais seriam um novo gênero do cinema "convencional"? Essa questão remete ao alerta de Joan Scott ${ }^{4}$, muito citado, mas pouco investigado, sobre a "inclusão" das mulheres na pesquisa histórica de forma suplementar, apenas descritiva. Indagar sobre o que se vê nestes festivais, dentro e fora das telas, é perguntar se há apenas a busca por apresentar a "comunidade", o que é e o que gostaria de ser,

3 Não é possível explorar, neste artigo, a relação dinâmica que penso existir entre a formatação e a sociabilidade constitutivas dos festivais analisados e a constituição mesma da própria vida urbana, mas concordo com autores que analisam essas correlações e conexões entre a vida gay e o ritmo das cidades, dado que um alimenta o outro. Ver os trabalhos de George Chauncey (1994) e de Matt Houlbrook que, logo na introdução, argumenta: "Ser 'queer' se tornou equivalente à experiência cultural da vida urbana". Segundo o autor, esse fenômeno está presente em diferentes estudos históricos sobre sexualidade, principalmente depois do groundbreadking História da sexualidade, de Michel Foucault. Ao analisar autores como Jeffrey Weeks, John d'Emilio, Henning Bech, Houlbrook (2005:8), de modo inovador, desenvolve uma importante crítica sobre a cidade não apenas como o lugar da liberação (já que os laços familiares estariam mais enfraquecidos, a possibilidade do anonimato muito mais adequada, a mobilidade, etc.), mas evoca este espaço também como alienante.

4 Scott, 1999:199-222 - "Some more reflections on gender and politics". 
Os festivais GLBT de cinema

ou se existem tentativas de suscitar novas questões a essa comunidade e aos "outros" possíveis espectadores (retomando aqui a velha polêmica real versus vir-a-ser). Finalmente, há a dobra provocada pelo meu olhar historiográfico que percorre as subjetividades em foco nesta análise.

A produção de um filme implica uma forma de abordar temas clássicos dos relacionamentos humanos - tristeza, lidar com perdas e frustrações, disputas e rivalidades, lutas amorosas, paqueras e conquistas. Ao "montar" a cena, produz-se e descrevese uma territorialidade afetiva e política. Por isso, a cada filme, podemos indagar: essa territorialidade subverte o quê? Dialoga com o quê? Desloca as formas de assédio e humilhação de corpos efeminados (sejam de homens ou de mulheres)? Qual masculinidade é colocada como "desejante" e desejada? Não se trata aqui de fazer uma crítica ou resenha dos filmes ou dos festivais, mas problematizar a economia erótica produzida nesse circuito, percebendo seu alcance de crítica e deslocamento da heteronormatividade. ${ }^{5}$

Antes de passar à análise, apresento um breve panorama dos Festivais e das "paradas" na tentativa de circunscrever as condições históricas nas quais os filmes analisados foram produzidos e exibidos, uma vez que se configuram como parte significativa de suas condições de existência.

\footnotetext{
${ }^{5}$ No artigo Gender is burning... Judith Butler faz uma rica análise de Paris is burning (1991, dir. Jennie Livingston), que pretendia ser um filme que apresentaria a vida queer (em especial de drag queens e da transexual Venus Xtravaganza) em toda a sua potência e extravagância, documentando um lado mais "verdadeiro" e menos estereotipado da vida in drag. No entanto, esse aspecto "revelador", conscientizador, do filme foi bastante criticado, inclusive pela própria Butler. Tomo como central para a minha leitura, tanto dos filmes quanto dos Festivais de cinema, o argumento de Butler de que nem sempre a apropriação paródica subverte e/ou desloca o falocentrismo e a heterossexualidade compulsória, pois, muitas vezes, recai em representações dicotômicas, construindo performances que mais reiteram as normas do que as subvertem (Butler, 1993:23).
} 
Karla Bessa

\section{As "Paradas" e os Festivais}

Guardadas as diferenças, desde o início, houve uma ligação entre os Festivais e as Paradas do Orgulho Gay, não apenas pelo ponto de partida - São Francisco, na década de 1970 -, mas pela referência à constituição de espaços de sociabilidade, de encontro entre gays, lésbicas, transgêneros, bissexuais. Nesse sentido, o objetivo era fazer com que cada um saísse do seu próprio universo - bares, festas e guetos -, criando, em primeira mão, uma tolerância à diversidade interna da "comunidade" ${ }^{6}$, cujas diferenças nem sempre foram negociadas harmonicamente.

Ao incluir outras marcas de diferenciação - classe, raça $e$ nacionalidade $-e$ ao adentrar em práticas eróticas e de estilização corporal - sadomasoquismo, fist-fucking ${ }^{7}$, cross-dressing, usos de tatuagem e piercing -, os festivais ganharam um contorno abrangente que instigaram a produção e difusão de toda uma gama de "novas subjetividades" e, de certa maneira, atuaram (e continuam atuando) não apenas na constituição de performances de gênero, mas também na configuração de novas formas de expressões de prazer, desejo e sexualidade. Refletir, sobretudo, sobre as décadas de 1980 e 1990 do século XX implica perceber como os filmes exibidos estiveram vinculados às lutas (simbólicas ou não) políticas, éticas e estéticas que vão desde a reposição do "casal", nos moldes dos parâmetros "hetero", até seu avesso, como a exploração de técnicas e outros coadjuvantes eróticos, configurando um jogo com regras, às vezes, rígidas, porém, circunstanciais.

\footnotetext{
${ }^{6}$ A perspectiva comunitária denominada "glbt" aparenta ser menos volúvel do que a Cloakroom community descrita por Z. Baumann (2001:229): "[essas comunidades] dão um alívio temporário às agonias de solitárias lutas cotidianas, à cansativa condição de indivíduos $i$ de jure persuadidos ou forçados a puxar a si mesmos pelos próprios cabelos".

7 O Fisting ou Fist-Fuck é uma prática sexual que envolve a inserção da mão, algumas vezes do braço, no ânus, reto e intestino (quando anal) ou vagina, seja em parceiros hetero ou homo (masculinos e femininos).
} 
Os festivais GLBT de cinema

Outro dado que liga os festivais às "paradas" ${ }^{8}$ é a possibilidade de construir uma dada visibilidade - ainda que tímida nos anos 1970 e restrita a algumas poucas cidades (São Francisco, Chicago) e só nos anos 1980 estendida para Nova York, Londres e Paris - assumidamente exótica (homens seminus, montados como drags, bonecos, mulheres travestidas), às vezes carnavalesca, ou até grotesca. Nos primeiros atos públicos dessa natureza, o objetivo manifesto era reviver o sofrimento dos que participaram e perderam suas vidas durante os confrontos de Stonewall (1969), mas, aos poucos, a irreverência passou a agregar uma atitude propositiva, quando, em 1979, já com as ruas anualmente ocupadas, São Francisco celebrava os 10 anos de Stonewall com o slogan: "Um exército de amantes não pode falhar" (tradução literal!). Pela foto é possível notar a presença das bandeiras de arco-íris, ainda hoje utilizadas, e, embora não estivesse lotada, a avenida fora literalmente tomada por ativistas $e$ simpatizantes da causa gay.

\footnotetext{
8 Não é objetivo deste artigo fazer um histórico das "paradas", mas algumas informações são relevantes para este debate. Em 1970, realizou-se a primeira marcha nas ruas de São Francisco, com o nome de Gay-In. Em 1972, não houve essa manifestação, naquela ocasião ocorreram duas paradas - Gay freedom day e Gay Liberation Festival. No ano seguinte, uma organização conseguiu unir os dois movimentos e realizar uma atividade conjunta. A partir de 1973, a "parada" passou a ser realizada anualmente. Destaco o tema da "parada" de 1975, pois é justamente o lema que provoca todo um debate, tanto no movimento quanto nas suas bordas, e mobiliza o "entorno" dos festivais e lhes dá um objetivo claro, ainda em vigor na principal página do site do mais antigo de Festival GLBT de filme e vídeo: "Junte-se a nós, quanto mais visíveis somos, mais fortes ficamos".
} 
Karla Bessa

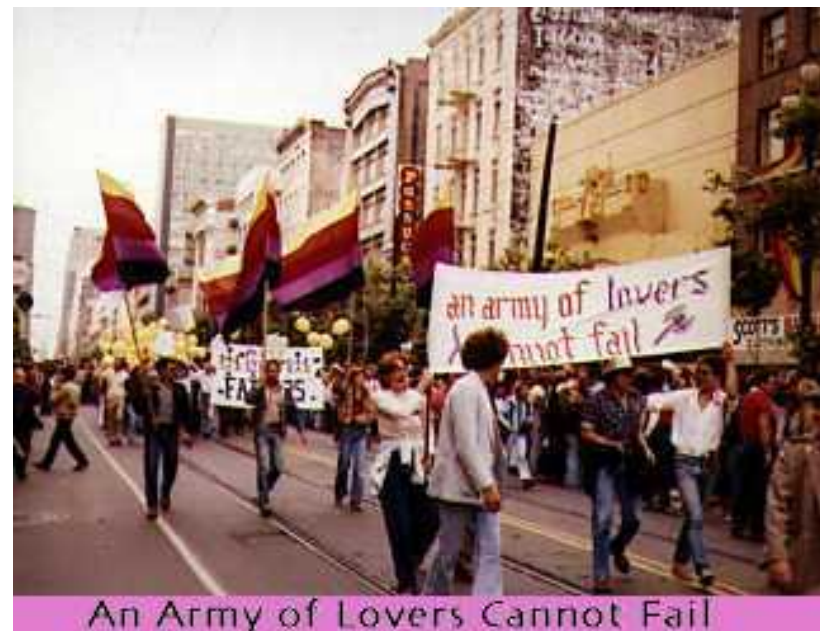

Fonte: http://thecastro.net/parade/parade/parade.html

Um dos desafios iniciais do "festival" era criar um espaço de produção e exibição de filmes que estabelecesse um diálogo entre a pluralidade de sujeitos e subjetividades pertencentes à cena "homo". Promover a ruptura com o padrão estético da sissy (gay efeminado $)^{9}$, com cenas de erotismo entre mulheres direcionadas para a libido masculina heterossexual -, ou, ainda, personagens gays vinculadas à criminalidade, monstruosidade,

\footnotetext{
${ }^{9}$ Há um curto, porém instrutivo artigo que mapeia os filmes americanos que lidaram com personagens sissies e consolidaram esta imagem. Embora a ênfase esteja voltada para os filmes produzidos nos anos 1930 e 1940, o artigo traça com clareza o que posteriormente será bastante criticado pelos novos produtores do cinema queer. Para Gary Morris (2002), há um misto de fascínio e medo de que o perfil sissy marque um padrão depreciativo da imagem homossexual masculina: "como espelho distorcido da masculinidade, o sissy fascina tanto como um desafio às rígidas normas masculinas quanto como um reforço delas. Sua simples presença próximo ao macho (ou fêmea) heterossexual frequentemente como camareiro, decorador, amigo fiel, ou, mais tarde, na confusão que irrompeu em torno da imagem, rival romântico - lembra sutilmente a audiência de que há outras maneiras de ser, talvez mais satisfatórias, do que a heterossexualidade convencional".
} 
Os festivais GLBT de cinema

fadadas a finais trágicos reservados aos que se permitiam participar das mais grotescas perversidades..$^{10}$ De certa forma, havia uma consciência clara sobre a importância de construir uma auto-representação ${ }^{11}$, cuja aposta política estava vinculada ao compromisso de subverter a imagem hegemônica veiculada sobre a homossexualidade pela indústria cinematográfica.

No layout dos sites ${ }^{12}$ dedicados aos festivais, percebe-se nitidamente uma compreensão dos agentes promotores dos

\footnotetext{
${ }^{10}$ Uma leitura crítica das personagens gays nos filmes do mainstream hollywoodiano foi realizada no famoso livro de Vito Russo (1987), que serviu de base para o roteiro do filme de mesmo título, escrito, produzido e dirigido por Rob Epstein \& Jeffrey Friedman (101min, USA, 1996). Neste livro, o autor defende o argumento de que desde o início do cinema há gays em cena, mas são representados de uma maneira homofóbica. Os anos de censura teriam acentuado ainda mais o tom de segredo dado aos assuntos da vida homossexual, embora uma leitura a contrapelo das situações e personagens desvelasse a existência desta "subcultura" (Harmony, 1998).

${ }^{11}$ Teresa de Lauretis chama atenção para este mesmo aspecto ao analisar a filmografia produzida por mulheres comprometidas com um projeto feminista, ou mesmo, quando analisa diretores como Fellini. Há uma passagem que teve um impacto especial na minha postura analítica do cinema queer, que reproduzo aqui: "A subjetividade de gênero do espectador está implicada e é construída (como auto-representação) na representação cinemática. $\mathrm{O}$ que deve ser ressaltado outra vez, pois o gênero não é um fato, um dado, mas sim uma representação, cujo status (valor de verdade, peso moral ou epistemológico, etc.) e grau de realidade (objetiva a subjetiva) variam segundo a hierarquia social dos discursos e das representações. Assim, a subjetividade de gênero de cada um não está só implicada, como no encontro do espectador com cada filme, mas também é construída, reafirmada ou desafiada, deslocada ou mudada, no processo de ver cada filme" (Lauretis, 1987:96).

${ }^{12}$ Uma das melhores descrições sobre a força agregadora dos festivais e sua especificidade em relação a outros espaços gays de sociabilidade está em Rich e Steele (1999:50): “....Nesta era de super-conectividade cyber que existe ao lado do isolamento no mundo real, os festivais ainda são um lugar chave onde os gays e lésbicas locais se reúnem para afirmar-se e reinventar-se. São um lugar único, não inteiramente público nem privado, não um bar nem uma parada, onde audiência significa real e verdadeiramente comunidade". $\mathrm{O}$ autor menciona, ainda, o fato de que, com a afirmação e difusão dos festivais, ocorreu
} 
festivais sobre o lugar privilegiado do cinema ${ }^{13}$ nas sociedades contemporâneas, marcadas por um acelerado desenvolvimento tecnológico dos meios de comunicação de massa e diversificação das atividades de lazer e circulação de "bens" culturais, principalmente após a segunda metade do século XX. Nesse sentido, os festivais investiam e investem na concepção de um cinema-divertimento, mas, sobretudo, na auto-representação das lutas travadas contra a homofobia, na crítica à heterossexualidade como norma, e na valorização daquilo que os estereótipos ridicularizavam - a "sapatona" e seus maneirismos masculinizados, a travesti, as drag queens e seus exageros visuais, o lugar entre reservado aos transexuais, as barbies e seus musculosos corpos, a lésbica intelectualizada, uma população que, por vezes, se auto-denominou freak ${ }^{14}$ e vivia, de um jeito queer ${ }^{15}$

também o crescimento e fortalecimento da própria audiência que agora se predispõe a conferir as novidades dos festivais.

${ }^{13}$ Entre vários depoimentos que aparecem no filme Celluloid Closet, Tony Curtis diz que sua sensibilidade e muito do seu comportamento foi "modelado" com as imagens de Gary Grant, entre outros do cinema. As falas dos entrevistados enfatizam a eficácia das imagens cinematográficas na construção da sensibilidade moderna. Harvey Fierstein, um dos atores entrevistados, menciona a "fome aparentemente infantil por imagens gays" e depõe a favor das personagens sissies; para ele, ainda que as personagens sissies componham um tipo caricatural do gay efeminado, não necessariamente são imagens agressivas para os gays em geral, pois muitos podem se identificar com este perfil (ele próprio disse ser uma sissie), embora reconheça que seja um estereótipo utilizado para a discriminação.

${ }^{14}$ O filme Freaks (1932), dirigido por Tod Browing, traz uma cena memorável de uma festa de casamento entre um anão e uma belíssima mulher, criando um exagero "grotesco" que, ao mesmo tempo, provoca riso e incômodo, não apenas pelas assimetrias físicas, como também pela maneira como a alteridade é ali violentamente focada (a bela mulher sofre uma cena de violento esquartejamento que a torna uma "igual", literalmente monstruosa!). Ao analisar criticamente este filme, Mary Russo (1994) expõe o que entende ser a reapropriação, nos anos 1960, do termo "Freak", da ambigüidade com a qual se relaciona com os "real freaks", apresentando algumas armadilhas dessa forma política de apropriação de uma identidade que, de certa maneira, vulgariza a dificuldade da sociedade de lidar com outras corporalidades, como as 
Os festivais GLBT de cinema

(na tela e fora dela), a possibilidade de conquistar visibilidade, cuja conotação não fosse mais a da perversão, mas da ousadia e da beleza de ser e se reconhecer diferente, sem necessidade de vínculos a identidades essencializadas e de demarcar políticas identitárias em sua construção fílmica.

Diferentes performances de gênero e desejo se confundiam na expectativa que perpassava a constituição dos festivais, que se transformavam, dessa forma, em lugares também de tensão e divergências. Para alguns organizadores dos festivais, os filmes "independentes", com baixíssimo custo, técnicas simples $e$ até mesmo sem preocupação e conhecimento estético cinematográfico, deveriam trazer o apelo do reconhecimento. $\mathrm{O}$ objetivo era de que nas salas de exibição ocorresse a sensação de partilhar algo, de desfrutar da "compreensão", minimizando dores

"aberrações" circenses (gêmeos siameses, mulheres barbadas, anões, etc.), que faziam espetáculos de suas "diferenças" como forma de sobrevivência.

${ }^{15}$ No site no qual encontramos o artigo Transvestism in film, de Andrew Grossman, há um link que remete à uma das definições de queer: "Originalmente um sinônimo de esquisito (odd), esse termo - como substantivo e como adjetivo - se tornou um epíteto pejorativo para homens gays e lésbicas no século vinte, especialmente nos Estados Unidos, onde sublinhava a "não naturalidade" da homossexualidade. Embora muitas pessoas ainda usem queer como insulto anti-gay, na década de 80 surgiu um movimento que procurava resgatar o termo e livrá-lo de seu significado negativo. Neste uso, queer é um guarda-chuva que designa todos aqueles que são sexualmente dissidentes, mesmo que não sejam estritamente homossexuais, $e$ todas as formas "transgressivas" de sexualidade. Muitas lésbicas e homens gays, transexuais, bissexuais e mesmo heterossexuais cuja sexualidade não cabe no padrão cultural do casamento heterossexual monogâmico adotaram o rótulo queer. Alguns homens gays e lésbicas, porém, lembrando as feridas causadas pelo sentido pejorativo, não gostam do termo, mesmo resgatado dessa forma, e sentem que ele tem o efeito de diluir a especificidade das categorias mais estreitas. O termo é às vezes usado como verbo. "Queer" alguma coisa é substituir valores heterossexuais, normativos, por valores das sexualidades minoritárias, efetivamente fazer dos valores não-normativos a norma" (negritos meus). http://www.glbtq.com/arts/transvestism_film.html. Acesso em fevereiro de 2005. A publicação do artigo é de 2002, e o site é uma "Enciclopédia da gay, lésbica, bissexual, transgenera e queer cultura", produzida em Chicago, EUA 
e sentimentos de isolamento. Mas como isso se tornou viável? Quais condições possibilitariam tal exercício de identificação social e psíquica? Uma das estratégias percebidas durante a análise de alguns filmes exibidos nos festivais é a da verossimilhança. Uma busca em ver na semelhança entre espectador e espetáculo que se é "real", como se a verdade de sua própria realidade estivesse garantida no jogo de representação que ocorre no lugar entre a tela e a poltrona. ${ }^{16}$

Essa constatação levou-me a uma pergunta: os festivais seriam momentos (rituais) de mera acomodação daquilo que já se sabia ser uma confirmação da identidade ou haveria espaço para abrigar as tensões de gênero e da sexualidade? Tal questão só pôde ser pensada nas brechas que escaparam aos próprios realizadores, mesmo quando a intenção era carregada de reforço identitário, ou de tentativa de escapar das categorizações e identificações e encarar as tensões e paradoxos do desejo ${ }^{17}$ (e ocorria o inverso).

Nesse sentido, a problemática que me guiou (e guia) é, para além dos festivais, perceber, nas histórias fílmicas - na maneira como exploraram e expõem cenas de intimidade, desejo e paixão homoeróticas, bem como sofrimento, enclausuramento $e$ narrativas de lutas travadas pelo movimento de liberação gay e contra a AIDS - se há abertura para reconstrução de uma nova forma de encarar os limites estreitos da sexualidade e de um jeito de viver para além das normas restritivas de gênero, desejo e prazer, sejam elas "hetero" ou "homo".

Filmes como Stonewall (1995), Paragraph 175 (2000), Before Stonewall (1984), After Stonewall (1999) fazem parte, junto com o rol de discursos e imagens proliferadas principalmente a partir da segunda metade do século XX, da busca e produção de

\footnotetext{
${ }^{16}$ Uma fantasia partilhada excede e ganha força para sobreviver. Lembro aqui a análise de J. Butler (2004:142) sobre a personagem de Teena Brandon e de sua namorada Lana.

${ }^{17}$ Neste caso, merece destaque o instigante filme de Almodóvar, La Ley del Deseo (Espanha, 1987), que ganhou o Teddy no Festival de Berlim, em 1987.
} 
Os festivais GLBT de cinema

conhecimento sobre o "eu" e a humanidade em geral, na medida em que problematizam sua própria definição como "universal", ao trazer para o primeiro plano as diferenças de gênero e o quanto a noção de "humano" sofre os efeitos desta marca.

De certa forma, o cinema, não só o queer, participa daquilo que Foucault localizava no discurso científico moderno - os jogos de produção da verdade -, os quais, de diferentes maneiras, os seres humanos utilizam para elaborar um saber sobre eles mesmos ou, em suas palavras, que estão ligados aos "(...) 'Jogos de verdade' que são ligados às técnicas específicas que os homens utilizam para compreender o que são" [Foucault, 2001:1602-1632]). Foucault menciona quatro grandes tipos de tecnologias - de produção, dos sistemas de signos, de poder e do "eu" (self). Em suas últimas pesquisas, o autor enfatiza o encontro entre a tecnologia da dominação (ou do poder) e a tecnologia do eu, justamente porque neste encontro ocorre o fenômeno político da gouvernementalité..$^{18}$ Essas reflexões de Foucault, apropriadas no contexto desta análise sobre os festivais, sinalizam e requerem uma análise que considere esta produção - seja da identidade gay (gayness), seja da prática queer ${ }^{19}$ - a partir de seus respectivos

${ }^{18}$ Foucault (2001:160) define a governamentalidade como "o encontro das técnicas de dominação exercidas sobre os outros e as técnicas de si-mesmo".

${ }^{19}$ Refiro-me aqui àquelas práticas culturais que, diferente de uma perspectiva naturalista ou sócio-determinista, compreendem as diferenças entre gênero $e$ sexualidade de um ponto de vista histórico não teleológico, ou seja, sem visar a construção de uma coerente e normativa identidade homossexual. Ao chamar a atenção para esse termo, Teresa de Lauretis (1991) propôs uma distinção entre queer e estudos gays e lésbicos, cuja perspectiva era opor homossexualidade à heterossexualidade, uma como norma e outra como marginal, suscitando um importante debate sobre o caráter transgressor que naqueles estudos era praticamente inerente ao status de "homossexual". Em parte, é justamente por esta compreensão crítica atribuída aos estudos queer, cuja política, nas palavras de Halperin (2000: 86-91), "si quiere seguir siendo queer, debe ser capaz de vaciar lo queer de su referencialidad y positividad, cuidando su tendencia a encarnarse de manera concreta, preservando lo queer como una relación de resistencia más que como una sustancia de oposición". A despeito das críticas à mercantilização do termo ou à sua "vocação" elitizada (branca, intelectualizada), 
embates político-estéticos. Seguindo esta trilha, outras reflexões são possíveis.

Seria correto indagar se há o cuidado de si no final do século XX, como sugerem películas cinematográficas que abordam uma trama afetiva, erótica e ou política (institucionalizada) gay? Talvez não nos termos postos pela pesquisa de Foucault. Embora jogue com a estética $e$ a sexualidade na produção de modos de sujeição $e$, ao mesmo tempo, de auto-nominação, o cuidado de si, nos nossos tempos, se afastou da faceta ética que o norteava, gerando uma sensação de superficialidade e fluidez distinta da relação que Foucault fazia com o devir - não parte de e nem chega a nenhuma essência, mas cria modos de existir temporais, portanto, carregados de tensão, memória, matéria, mas que só constituem unidades em movimento (estruturas [des] estruturantes). Foucault ressalta, ainda, a diferença entre o cuidado de si e o conhecimento de si (do oráculo de Delfos). O conhecimento de si ficou mais premente na tradição filosófica $e$ vai constituir a grande diferença entre a maneira como a antiguidade lidava com a relação cuidado-conhecimento de si e a modernidade ${ }^{20}$, mas um é indissociável do outro.

Ao ler o texto de Platão e analisar as preocupações que cercam Sócrates e Alcebíades, Foucault comenta a máxima que dali se retira: "quando se cuida do corpo, não se cuida do self (si)". Na cultura de consumo ${ }^{21}$ em que vivemos parece que a equação é outra: cuida-se de si ao cuidar do corpo. E como o self remete a um senso de identidade coerente, há uma certa confusão

partilho deste aporte para pensar a construção do gênero e da sexualidade nos filmes e nos festivais aqui analisados, em detrimento de me situar exclusivamente no feminismo, nos estudos de gênero ou, ainda, nos estudos gays e lésbicos, como sugere o recorte desta pesquisa.

20 "...na cultura greco-romana, o conhecimento de si apareceu como conseqüência do cuidado de si. No mundo moderno, o conhecimento de si constitui o princípio fundamental" (Foucault, 2001:1608).

${ }^{21}$ Faço referência aqui à maneira como M. Featherstone (1995) analisa a estetização da vida cotidiana nos dias atuais. 
Os festivais GLBT de cinema

com essa relação de identificação (normativa) entre corpo-gênero, corpo-eu. Cuidado de si pode ser tomado como cuidado do corpo (visto como embelezamento, às vezes "saudável"), mas também como o encontro revelador de uma essência ou verdade escondida do "eu", que poderia ser entendido como "sair do armário" e assumir sua verdadeira essência, recôndita e reclusa. É justamente a esta maneira de se construir uma verdade (conhecimento e também cuidado) de si que Foucault difere, quando apresenta sua análise sobre a história da sexualidade, afirmando que o "gayness" não é bem uma descoberta, mas uma criação político-estética, temporal e, portanto, a naturalidade com a qual se torna um "padrão" reconhecível é mais um efeito de verdade do que uma verdade em si.

David Halpherin (2000) alerta para a grande diferença na maneira como hoje se entende essa relação com o self e a reflexão de Foucault, pois, nesta, fica implícita que o lugar do cuidado de si é o da alteridade, onde o sujeito encontra em si mesmo não a profundidade do seu eu, mas o mais além:

En lugar de apuntar a una realización personal, la antigua cultura de si actualizaba una esencia impersonal - uma cualidad moral más general tal como la moderation (sophrosyné) o una capacidad intelectual tal como la razón. En estas concepciones, la estilización de sí buscaba purificar el alma individual de todas sus características accidentales a fin de reunirla con la mente universal (Halperin, 2000:98).

Embora o cinema pudesse ser um lócus privilegiado para um cuidado de si nestes termos, a percepção que a leitura dos filmes cria é que distamos muito desta postura ética. No início do filme-documentário Word is out a montagem das cenas intercala os depoimentos, fragmentando as narrativas, mas mantendo sempre um fio condutor: o jogo de construção de uma memória de si (da infância ao presente) dá sentido libertador ao ato de "assumir" (e, portanto, poder falar publicamente sobre o assunto!) a condição gay ou lésbica. O espelho é envolvido no enredo como 
um dos primeiros elementos nessa "produção" identitária. Daí, a imagem, a auto-imagem, a mais do que vital relação $e$ fascínio com o filme, a relação entre o projetado na tela e aquele que, "aparentemente" passivo, se vê nesse grande espelho. Luz e sombra circunstanciando o cultivo do "eu".

Se não há intensificação subjetiva e sim uma conformação da subjetividade a um novo padrão - o "homo" -, será que essa prática seria apenas uma paródia despojada da tecnologia do eu? Ou nos surpreenderíamos ao ver justamente o contrário, um refinamento da tecnologia do eu, na relação entre imagemrepresentações (ou imagem-imaginário?), de grande flexibilidade e fluidez, configurando uma extensa gama de possíveis subjetivações? Uma proliferação performativa que explodiria a díade homo x hetero? No fundo, a questão que se persegue (eu também!) é saber como se dão os jogos neste olhar para os festivais, filmes e seus arredores - como ocorre a constituição do eu "gay"22 e o quanto ela reitera ou subverte essa possível identidade em termos de identidade sexual ou não.

Dos esparsos e tímidos Festivais da década de 1970 às mais de 100 edições anuais diferentes espalhadas pela Europa, Ásia, África, América do Norte (cerca de 60 só nos Estados Unidos), América Central e Brasil, pode-se dizer que a partir da década de 1990 a "homocultura" invadiu a grande mídia, criando o que ficou conhecido por "gay mainstream". ${ }^{23}$ As personagens dos novos

${ }^{22}$ Foucault (2001:1632) termina este instigante texto com uma hipótese sobre a técnica que teria tido maior impacto e estaria ainda presente: "A hipótese que me inspira o estudo dessas duas técnicas é que foi a segunda... a verbalização... que se tornou mais importante. A partir do século XVIII e até o presente, as "ciências humanas" reinseriram as técnicas de verbalização num contexto diferente, fazendo delas não mais o instrumento positivo da constituição de um novo sujeito. Que a utilização das novas técnicas tenha deixado de implicar a renúncia do sujeito a si mesmo constitui uma ruptura decisiva".

${ }^{23}$ Este termo foi utilizado na resenha de Michel Schwartz (1997:48) sobre o livro Anti-gay culture, editado por Mark Simpson. Embora o livro traga a reflexão sobre o que o autor considera os "excessos" da cultura gay - "a mediocridade da corrente dominante da cultura gay - a mentalidade "gay é bom" -, Simpson 
Os festivais GLBT de cinema

programas de TV são o termômetro dessa visibilidade, entre outros, Will \& Grace, Queer eye for straight guy, Ellen, Angels in America, Six feet under, Queer as folk e o mais recente $L$ word, seriados de grande sucesso nos EUA e, em alguma medida, em países onde são transmitidos em circuito fechado de TV.

Guardadas as proporções de quem tem acesso à TV paga nos países "periféricos", como o Brasil, e nos países nos quais a renda per capita é elevada, pode-se dizer que nesta virada de milênio, de diferentes maneiras, houve um boom de personagens e situações de homoerotismo nas telas. Não esquecendo que, antes do cinema e da televisão, o teatro havia popularizado certas cenas e situações, tais como as peças Angels in America ${ }^{24}$ e Lucky. ${ }^{25}$

Ainda com relação à rápida $e$ intensa mudança na trama das imagens, no recente livro lançado nos EUA - The Queer movie poster book -, Jane Olson (2004), crítica de cinema e cineasta, aponta as estratégias de divulgação dos filmes por meio dos cartazes, pôsteres, chamadas e vinhetas. A autora enfatiza que

questiona os autores da coletânea por analisarem esta cultura pressupondo uma tendência monolítica que, para ele, não existe e que as críticas caem no vazio, quando tentam recolocar, na contraposição a uma cultura gay dominante, uma cultura gay mais transgressora: "essas vozes clamam por uma forma mais transgressiva de ser gay". De maneira muito pertinente, o autor questiona se estes autores da coletânea não levavam estes debates acadêmicos a sério demais.

${ }^{24}$ A peça Angels In America: a gay fantasia on national themes (primeira parte), escrita por Tony Kushner, estreou em San Franciso em 1991 e foi ambientada em New York na década de 1980, trazendo à baila uma reflexão sobre a AIDS, o "armário", as contradições entre as falas de "democracia" na América e a homofobia, bem com o os conflitos religiosos, esse trio dá o tom político da mesma.

${ }^{25} \mathrm{Na}$ peça Lucky, o dramaturgo explora a dificuldade de caracterizar e descrever a sexualidade, questionando a perspectiva da identidade sexual como algo determinista. Expressões como "homnisexual, multisexual, unstraight, dodgy, trisexual" são utilizadas justamente para deslocar o lugar da identidade sexual na vida das pessoas. O autor estava, na época, com 22 anos e, de certa maneira, a peça é um retrato da insatisfação de parte da queer community com the labeling of sexuality (Glitz, 2001:53). 
todo o trabalho de marketing era estrategicamente pensado para atrair certos públicos, driblar a censura, sensibilizar e formar simpatizantes. Na apresentação, Olson relembra que a idéia do livro surgiu no início dos anos 1990 e levou quase uma década para conseguir financiamento e condições de ir para as prateleiras das livrarias de grande porte dos EUA.

$\mathrm{Na}$ parte dedicada aos filmes dos anos 1990, a autora comenta que se naquele período era possível exibir na grande mídia trailers com cenas explícitas - como ocorreu com Poison, que exibia, pela primeira vez em trailer, uma cena de beijo entre dois homens -, nos anos antecedentes, a censura prévia exigia cortes deformadores das películas e demandava um minimalismo que beirava a códigos secretos que só mesmo os "entendidos" decifravam. Neste cenário, os festivais, acabaram se tornando o lócus de maior explicitação deste (sub)mundo, antes muito mais restrito.

A maioria dos festivais, ao longo de suas edições, desenvolveu uma prática de conversa, de debate, que os distingue dos demais festivais de cinema, dado o interesse "formativo" que lhe é inerente. A aparição nos festivais GLBT de diretores, atores e críticos, bem como o convite a pesquisadores da área da sexualidade, da psique e/ou relacionados com a temática em questão (violência física contra gays, AIDS, etc.), promove outra dinâmica de projeção-audiência, que descaracteriza a tradicional relação passiva e aumenta as chances de esclarecimento ou mesmo de germinação de dúvidas (existenciais ou não) que permitirão um prolongamento da exibição do filme a uma relação maior (engajamento?) com o que se consome em termos de imagem-representação.

Essa dinâmica, sem dúvida, acrescentou aos festivais um toque de politização, mesmo que aqui este termo não necessariamente signifique o compromisso com a agenda de um determinado movimento gay. Até porque, as forças políticas em jogo são bastante diversificadas e marcadas ora por problemáticas 
específicas, como os "queer of color" ${ }^{26}$, ora gerais, como a discussão sobre as fronteiras (se é que elas existem) entre a exibição do erotismo entre casais de mesmo sexo e a pornografia, ou a crítica feminista de que alguns filmes que retratam personagens drags ou travestis, na verdade, lidam com uma misoginia dissimulada, na medida em que troçam (às vezes violentamente, embora por meio da própria imitação) dos ícones considerados como próprios do universo feminino (por exemplo, o uso exagerado de maquiagem, fixação em coisas ditas "supérfluas", maneirismos gestuais, comportamentos histéricos etc.).

Para uma análise das várias transformações que a formatação dos festivais sofreu ao longo das últimas três décadas de exibição (pelo menos 10 festivais nos EUA são realizados há mais de 15 anos - o de São Francisco completou seu $30^{\circ}$ aniversário em 2006), seria necessário um olhar atento às mudanças sofridas na sua programação $e$ às exigências para a inscrição/seleção dos filmes. Esta pesquisa minuciosa fica difícil porque conta com mais de uma centena de festivais espalhados pelo globo. Embora haja ligação e mútua referência entre os mesmos e muitos filmes que circulam, em quase todos há também as peculiaridades de cada um, a relação com a comunidade local, a história de cada um para se efetivar na cena urbana de grandes metrópoles e de (poucas) cidades de pequeno porte, como ocorreu no interior dos EUA no final da década de 1990.

A experiência acumulada nesse circuito é extremamente rica. Os diferentes registros produzidos ao longo do percurso resenhas dos filmes, cartazes, vinhetas dos festivais, matérias de jornais, crescimento de uma crítica cinematográfica praticamente

${ }^{26}$ A cineasta Prathiba Parmar (1993:174) advertia que os festivais GLBT eram, muitas vezes, a única possibilidade de exibição do material por ela produzido, sem deixar de fazer uma crítica: "o que está ficando claro, porém, é que esses festivais são predominantemente programados por homens e mulheres gays brancos, que priorizam seus próprios constituintes, e assim marginalizam ainda mais os queers de cor". 
especializada no gênero "filme gay" - alimentam e instigam uma pesquisa mais extensa. É comum encontrar em editoriais dos próprios sites dos festivais uma avaliação sobre sua importância para a população gay ${ }^{27}$, que pode, muitas vezes pela primeira vez, sair do isolamento e "encontrar" seus pares nesses eventos.

\section{Visibilidade, auto-representação e paradoxos nos filmes}

Em 1992, a crítica estadounidense de cinema, B. Ruby Rich, escrevia um artigo comentando a aparição de um conjunto de filmes, exibidos fora dos festivais gays (no MOMA de New York e no Angelika), cunhando um termo que depois foi repetidamente utilizado para caracterizar uma nova tendência, a "queer sensation", como sugere o subtítulo do artigo: "New gay film: a queer sensation" (Rich, 1992:41-43).

Entre os novos filmes mencionados constavam Edward II (Derek Jarman), Swoon (Tom Kalin) e The living end (Gregg Araki). O que havia de comum entre eles? O que havia de novo? Primeiro, o fato de circular para além dos festivais gays e de ter conquistado a crítica e o noticiário da grande imprensa. Em segundo lugar, apesar de não partilhar uma mesma estética, B. R.

${ }^{27} \mathrm{~A}$ esse respeito, apresento dois depoimentos, um italiano e outro estadunidense: "Durante sua existência, o Festival de Cinema Gay e Lésbico de Turim alcançou objetivos raros: enfrentou uma questão que sempre foi ocultada pelo silêncio do preconceito, ajudou a disseminar conhecimento e informação, tornou visíveis trabalhos que se destinavam a serem vistos apenas por certos nichos de audiência, encorajou autores internacionais e pela primeira vez este ano premia os melhores com o dinheiro do Prêmio Ottavio Mai". (Lietta Tornabuoni, La Stampa, 14 ${ }^{\text {th }}$ april 1999). O festival de Turin iniciou em $1985 e$ em 2006 realizou a sua $21^{\text {a }}$ edição. Outra curiosidade sobre este festival de Turim é o subtítulo - From Sodom to Hollywood festival. "Este festival é importante por muitas razões. Muitas vezes, é a primeira vez que uma pessoa GLBT está diante de 1000 outras pessoas como ele ou ela. Ouvi muitas pessoas dizerem que era a primeira vez que perceberam que estava certo... olhar os outros celebrarem quem eram permitiu-lhes ficar mais confortáveis com quem eles/elas mesmos eram" (KENNEDY, Mariuth. Board President Friends of the Festival. Tampa International Gya and Lesbian Film Festival, 2004). 
Os festivais GLBT de cinema

Rich considerava, em sua análise, que "há traços em todos eles de uma irreverente apropriação e pastiche, assim como trazem uma releitura da história tendo em mente o construcionismo social" para abordar a identidade gay. ${ }^{28} \mathrm{Um}$ dos elogios ao novo cinema é a retomada do caráter artístico dos filmes, reelaborando as estratégias narrativas comprometidas com as tragédias que afetaram os gays, sobretudo nos anos 1970 e 1980, e que requisitaram uma linguagem politizada e engajada.

A preocupação de engajamento político de realizadores, produtores e dos que participam dos júris dos festivais, desde o primeiro, realizado em São Francisco (1976), sempre foi justificada em face de uma leitura de que até meados dos anos 1980 a maioria dos filmes apresentava uma visão bastante distorcida dos gays, reforçando estereótipos e (re)alimentando a homofobia. ${ }^{29}$ Assim, essa produção cinematográfica deveria trazer uma nova abordagem, uma afirmação da identidade, bem como tocar nos problemas candentes enfrentados pelos gays no dia-a-dia.

${ }^{28}$ Rich (1992:4) descreve as características do novo cinema gay: "É claro que os novos filmes e vídeos queer não são a mesma coisa e não compartilham um único vocabulário ou estratégia ou interesse estético. E, no entanto, estão unidos por um estilo comum. Chamemo-lo de promoção Homo (Homo Promo): há em todos eles traços de apropriação e pastiche, ironia, e também um re-trabalhar da história com o construcionismo social em mente. Rompendo definitivamente com abordagens humanistas mais antigas e com os filmes e fitas que acompanhavam a política da identidade, essas obras são irreverentes, enérgicas, alternadamente minimalistas e excessivas. Acima de tudo, estão cheias de prazer. Estão aqui, são queer, ligue-se neles".

${ }^{29}$ Uma análise próxima foi realizada por Moreno (2001:278), que passeia pela cinematografia brasileira, analisando a comunicação e gestualidade das personagens homossexuais, detalhando sua análise filmica em 10 filmes para concluir que há sim a formatação (na produção discursiva deste cinema sobre o homossexualismo) "de um estereótipo", cujo teor pejorativo da abordagem da personagem é de 43,3\% no conjunto de 67 filmes analisados. Segundo o autor, "Estes filmes contribuíram para a formação de uma personagem-tipo do homossexual. E ainda, quando não condenam o comportamento da personagem, a utilizam como um gay clown, um homossexual palhaço, ou a colocam como algo depravado, doente, criminoso, freqüentador dos piores basfond" (Id. ib:280). 
Word is out ${ }^{30}$ sintetiza bem esse propósito no qual gays e lésbicas de diferentes idades, a partir de distintos backgrounds afetivos, narram sua própria experiência, relatando as barreiras familiares, as rupturas, as reações de amigos, colegas de trabalho, vizinhos, etc. Em depoimentos comoventes, as narrativas enfatizavam a importância de "sair do armário" e encontrar os pares, sentindo assim a acolhida própria ao gesto de pertencimento e de "normalidade" de uma situação social recriminada e mal entendida, para não dizer uma situação considerada mais grave do que a transgressão moral, portanto, compreendida como uma infração legal, passível de punição, ou uma patologia, passível de tratamento médico-psicológico.

O slogan "sou gay e me orgulho disso" representava, na fala dos entrevistados, um gesto libertador. A possibilidade do prazer $e$ da felicidade sem culpa. Word is out foi um marco para a constituição de imagens produzidas e voltadas especialmente para público gay e circulou pelos festivais, sendo exibido com destaque, em 2003, no $17^{a}$ London Lesbian \& Gay Film Festival e, relançado em DVD, faz parte da cinemateca básica da "cultura gay".

Se filmes com essa postura política foram tão importantes, por que tanta celebração do novo cinema queer, justamente na contramão do discurso identitário? O que estava em jogo neste artigo de Rich tão provocativo? No elogio ao filme The living end, Rich evidencia o que a atrai na história típica de filmes do gênero road movie - o fato de dois rapazes HIV positivos saírem sem rumo e sem nada a perder. Esse despojamento produziu um "filme existencial para uma era pós-pornográfica, que coloca os queers como sujeitos legítimos" (an existential film for a postporn

${ }^{30}$ Word is out. Mariposa Film Group, 1978, EUA. 130min, incluía como produtores Rob Epstein, Veronica Selver, Lucy Massie-Phoenix. O lançamento em vídeo ocorreu em 1996. Assisti a primeira versão, em $16 \mathrm{~mm}$, dirigida por Rob Epstein. 
Os festivais GLBT de cinema

age, one that puts queers on the map as legitimate genre subjects). ${ }^{31}$

O implícito na crítica da autora, usando os termos de Foucault, é o caráter confessional dos primeiros filmes, responsável por ligar a fala de assuntos reprimidos - sexualidade, desejo - à verdade mais íntima do ser que, uma vez posta a público, liberta o sujeito de seu infortúnio (no coming out). De forma semelhante, Mais outro do que os outros - Anders als die Andern [1919], filme alemão, dirigido por Richard Oswald -, conta com a presença do sexólogo M. Hirshfeld, cujo enredo narra a história de uma sociabilidade homoerótica marcada por bares, festas, lugares de encontros anônimos, com relativa liberdade especialmente durante a vigência da República de Weimar (que será praticamente extinta com a emergência do nazismo) restringida pela vigência do Paragraph 174, que condenava práticas homossexuais. No decorrer do filme há um julgamento (um médico, cansado de se ver vítima das chantagens por seu comportamento gay, ignora o chantagista que o delata) e um posterior suicídio, pois mesmo que os argumentos do Dr. Magnus Hirschfeld $^{32}$ resultassem em uma pena relativamente branda, o personagem sente-se terrivelmente marcado pela violenta experiência na qual sua vida amorosa e sexual tornara-se pública e sujeita ao escárnio. O filme termina com um discurso que evoca o número de casos de suicídio cometidos por pessoas que

${ }^{31}$ Como o texto foi escrito em 1992, ainda no início dos festivais gays pelo mundo, Rich propõe uma questão que merece atenção, depois de comentar como os filmes analisados foram bem aceitos no circuito americano e europeu (não com a grande configuração que tem hoje), ela pergunta: "Obterão as lésbicas a mesma atenção para suas obras que os homens têm obtido? E queers de cor, obterão o mesmo tempo?”. Neste último parágrafo do artigo, a autora faz um comentário bem otimista de que o mundo tem mudado o suficiente para haver um debate com uma cineasta lésbica e um gay, sentados lado a lado $e$ muitos colegas, preocupados com a história queer, com o poder de transformar a década "para ele, para ela, para todos nós"!! (Rich, 1982:5).

${ }^{32} \mathrm{O}$ doutor Magnus Hisrscheld foi responsável, juntamente com Richard Oswald, pelo roteiro do filme. 
passaram por experiências semelhantes de opressão e humilhação.

A autora parece localizar no cinema "queer" um outro modo de produção da subjetividade homoerótica, que ainda dialoga com a crítica à homofobia moralista, mas sem repor uma identidade necessariamente afirmativa e vinculada à naturalização legitimadora do caráter transgressor da homossexualidade. Essa cinematografia conseguiu escapar do essencialismo? Embora não reproduzam narrativas identitárias, receio que não conseguiram criar um outro imaginário no qual cultura e natureza não estejam em relação de determinação, particularmente em Edward II (Jarman, 1991) e Go fish (Troche, 1994). No entanto, concordo com Rich que há uma nova estética em construção que dialoga com as "novas demandas da "gay community" e, especialmente, parece haver um enfrentamento da diversidade interna e uma exposição sem moralismos dos aspectos contraditórios, às vezes violentos, de seus protagonistas, sugerindo uma diminuição do tom de vitimização na construção de algumas personagens.

A filmografia da década de 1990 colocou em cena toda a ambivalência política já presente no propósito dos festivais que, se aposta na construção de identidades de gênero, também fornece munição para estas mesmas identidades serem permeadas pelas instabilidades, frações e indeterminações que recolocam no lugar do discurso científico patologizante da homossexualidade ou das perversões sexuais outras possibilidades de vivência. No espírito dos film studies, a queer teory negocia com a gay and lesbian film criticism algumas fronteiras. Inicialmente, a crítica queer à gay theory era sua forma naïve, presa a essencialismos tão questionados, estabelecendo um ponto epistemológico de diferença ao considerar essa demarcação como dada de antemão - essência (substância) x não essencialismo (performance) e, como todas as dicotomias, obliterando as intersecções. Nesse sentido, a queer theory não é pura, tampouco o new queer cinema está isento de posturas clássicas nas lutas contra a normatividade heterossexual. Nos filmes aqui mencionados, a maior dificuldade 
Os festivais GLBT de cinema

foi enfrentar o falocentrismo e o lugar de reinado da sexualidade atribuído à subjetividade.

Nas representações do que somos, os vínculos mecânicos entre desejo, prazer e identidade sexual ainda são acionados, criando a falsa ilusão de uma continuidade e coerência entre estas diferenças, porém intercambiáveis, esferas da nossa subjetividade. O uso político do termo queer tem assim uma posição estratégica na luta contra a fixação de identidades trivializadas e normatizadas pelas práticas/discursos institucionalizados, apesar de sofrer os desgastes das apropriações da mídia e do mercado nos últimos anos.

\section{Referências bibliográficas}

Baumann, Zygmunt. Modernidade Líquida. Rio de Janeiro, Zahar, 2001.

BUTLER, Judith. Undoing Gender. New York, Routledge, 2004.

Bodies that matter. London/NewYork, Routledge, 1993.

CHAUNCEY, George. Gay New York: gender, urban culture, and the making of gay male world, 1890-1940. New York, Basic Books, 1994.

FeATHerstone, M. Cultura de consumo e pós-modernismo, São Paulo, Studio Nobel, 1995 [Trad: Júlio Simões].

FOUCAULT, Michel. Dits et écrits II, 1976-1988. Paris, Quarto Gallimard, 2001.

História da sexualidade. A Vontade de Saber (Vol. I). $5^{\mathrm{a}}$ ed. Rio de Janeiro, Graal, 1984 [Trad.: Maria Thereza da Costa Albuquerque e J. A. Guilhon Albuquerque].

HALPERIN, David. La política queer de Michel Foucault. In: San Foucault. Para una hagiografia gay. Córdoba, Edelp/Cuadernos de Litoral, 2000.

HARMONY, H. Wu. The Celluloid Closet: homosexuality and movies. International Gay \& Lesbian Review. Los Angeles, One Institute Press, 1998.

HOULBROOK, Matt. Queer London. Perils and pleasures in the sexual metropolis, 1918-1957. University of Chicago Press, 2005. 
GLITZ, Michael. Defying labels: twenty-something playwright Eddie de Oliveira questions the labeling of sexuality with his new work, Lucky. The Advocate, Aug. 28, Los Angeles, 2001.

DE LAURETIS, Teresa. Queer Theory: Lesbian and Gay Sexualities. An Introduction. Differences (3.2), 1991.

T. Technologies of gender. Essays on theory, film and fiction. Indianápolis, Indiana University Press, 1987.

MORENO, Antônio. A personagem homossexual no cinema brasileiro. Rio de Janeiro, Funarte-EdUFF, 2001.

MoRRIS, Gary. Film Sissies. The Queer Encyclopedia of the visual arts. Chicago, 2002.

Olson, Jenni. The queer movie poster book. San Francisco, Chronicle Books/LLC, 2004.

PARMAR, P. Queer questions: a response to B. Ruby Rich. In: CoOK, P. \& DODD, P. (eds.) Women and film: a sight and sound reader. Philadelphia, Temple University Press, 1993.

$\mathrm{RICH}, \mathrm{B}$. Ruby. The last refuge of democracy: a talk with B. Ruby Rich by Jannie Rose. 07/05/2004 www.greencine.com./article

; STEELE, Bruce C. Festival of Festivals: no longer just a footnote to Pride, lesbian and gay film fests are bringing exceptional cinema- and greater visibility - to towns across the continent. The Advocate. Aug 1, Los Angeles, 1999. 24, 1992

New gay film. A queer sensation. The Village Voice, March

Russo, Mary. The Female Grotesque: risk, excess and modernity. New York, Routledge, 1994.

Russo, Vito. The Celluloid Closet. New York, Harper \& Row, 1987 [1981].

ScotT, Joan. Gender and the politics of history (Revised Edition). New York, Columbia University Press, 1999 [1988].

SCHWARTZ, Michael. Resenha de Anti-gay culture, edited by Mark Simpson. The Harvard Gay \& Lesbian Review, vol. 4, Iss2, Apr. 30, Boston, 1997.

TREvisan, J.S. Devassos no Paraíso. A homossexualidade no Brasil, da colônia à atualidade. $3^{\mathrm{a}}$ ed. São Paulo/Rio de Janeiro, Record. 2000. 